\title{
Mechano-sensing and cell migration: a 3D model approach
}

\author{
C Borau ${ }^{1,2}$, R D Kamm ${ }^{2,3}$ and J M García-Aznar ${ }^{1}$ \\ ${ }^{1}$ Aragón Institute of Engineering Research (I3A), University of Zaragoza, Spain \\ ${ }^{2}$ Department of Mechanical Engineering, Massachusetts Institute of Technology, Cambridge, MA, USA \\ ${ }^{3}$ Department of Biological Engineering, Massachusetts Institute of Technology, Cambridge, MA, USA \\ E-mail: cborau@unizar.es
}

Received 16 June 2011

Accepted for publication 3 November 2011

Published 25 November 2011

Online at stacks.iop.org/PhysBio/8/066008

\begin{abstract}
Cell migration is essential for tissue development in different physiological and pathological conditions. It is a complex process orchestrated by chemistry, biological factors, microstructure and surrounding mechanical properties. Focusing on the mechanical interactions, cells do not only exert forces on the matrix that surrounds them, but they also sense and react to mechanical cues in a process called mechano-sensing. Here, we hypothesize the involvement of mechano-sensing in the regulation of directional cell migration through a three-dimensional (3D) matrix. For this purpose, we develop a 3D numerical model of individual cell migration, which incorporates the mechano-sensing process of the cell as the main mechanism regulating its movement. Consistent with this hypothesis, we found that factors, such as substrate stiffness, boundary conditions and external forces, regulate specific and distinct cell movements.
\end{abstract}

\section{Introduction}

The relevance that cell motility has gained in biological research reflects its major role in several physiological and pathological processes, e.g., morphogenesis, the inflammatory response, wound healing and tumor metastasis [1]. Generally, cell motility is guided by environmental signals or cues from the surrounding microenvironment $[2,3]$. These cues reflect the physical-chemical nature of the extracellular matrix (ECM) and its binding to transmembrane receptors, allowing cells to probe the mechanical properties of their environment and react in a specific way [4]. This ability of cells to sense ECM stiffness or pre-strain enables them to regulate their mechanical response and, therefore, its characterization is crucial for understanding their directional migration. It has become clear, in the last few years, that cells sense their surroundings by extending lamellipodia and filopodia that attach to the substrate, then exerting contractile forces in order to explore the mechanical properties of their environment [5]. These active forces are generated by myosin motors and are transmitted to the ECM by means of transmembrane proteins (integrins) that often cluster to form focal adhesions [6-8]. The influence of the stiffness and topography of the ECM is critical to this process, and has been recently investigated [3, 9-17]. One important finding is that cells prefer to migrate to the stiffer part of the ECM or substrate [9, 18-20]. Focal adhesions are more stable and contraction forces increase on stiffer substrates [9, 16, 18, 20]. However, whether cells are able to sense stress or strain is still unclear [21-23]. Furthermore, the application of external stress/strain on the cell also stimulates focal adhesion formation and subsequent strengthening [24, 25] and therefore, this stress can trigger molecular reorganization and cytoskeletal (CSK) adaptation.

Cell migration studies have primarily focused on migration on $2 \mathrm{D}$ substrates. These studies have helped to elucidate the mechanisms by which cells migrate, interact with the substrate or change their speed. However, when completely surrounded by the ECM, cells experience a different environment and some factors that were not present in 2D appear, such as the role of volume exclusion [26] and relevant differences in cell morphology, adhesions and signaling $[27,28]$. Therefore, to fully understand how cells migrate in vivo, it is necessary to study the movement of cells in 3D environments. In recognition of this need, experimental 3D cell movement studies [29-32] and modeling efforts [33-36] have been growing in number in the recent past. 
In fact, although most models for cell migration have been developed for 2D conditions, more recently, 3D models have appeared. All of these models may be classified as either continuum or discrete approaches. On one hand, most continuum models are based on reaction diffusion equations for cells and diffusive chemicals [37-39]. In general terms, these continuum approaches have the following limitations: they are valid only when there are weak cellto-cell interactions and they underestimate volume exclusion effects that are present in 3D [26]. On the other hand, discrete models have also been developed. These are of two main types: lattice models and interaction-force based models. The former ones can be subdivided into two approaches: cellular automata models [40] and cellular Potts models $[41,42]$. Their main limitations are that they do not include the role of cell mechanical properties and they are mainly phenomenologically based approaches, requiring many nonphysical parameters to be determined from experiments. Finally, the so-called force-based dynamics method [33] normally uses single cells as basic units, each of which is characterized by its location and orientation, its state of stress and the active forces it can exert in response to the local microenvironment. Knowing this for each cell, the velocity of each individual cell can be evaluated through the equilibrium of forces. Normally, the differences among models are based on the consideration of different kinds of forces that define this equilibrium. Using this approach, a mathematical model for cell movement in multicellular systems has been developed [43], incorporating viscoelastic properties of cells to simulate $3 \mathrm{D}$ cell movement during aggregation and the slug stage of Dictyostelium discoideum, embryogenesis, limb formation and wound healing. Three main forces are considered in this work: passive, active and a viscous drag force. The active force is due to a chemotactic signal and the passive force takes into account the elastic interactions between neighboring cells. Other force-based dynamics approaches [33-35] have been used to model the movement of individual cells in $3 \mathrm{D}$, considering a more realistic cell-matrix interaction and taking into account the receptor-ligand adhesivity. A recent study on single-cell migration in 3D has been presented, based on this approach [36], where chemotaxis as well as contact guidance are considered to regulate cellular movement. Although all these models take into account many different effects through the forces that regulate cell movement, to our knowledge, none of them have incorporated mechano-sensing. This mechanism is associated with the active contractile forces that cells exert on their surroundings in order to probe the mechanical environment [5, 44].

Here, we present a 3D migration model of a single cell, in which we hypothesize that mechano-sensing is the main regulator of its directional movement. Hence, we take into account the main mechanically relevant components of the cell, the contraction forces exerted on the ECM/substrate and the major phases in cell migration: mechano-sensing through cell contractility, cell polarization/adaptation that can influence directional cell motility by means of the formation of the leading and trailing cell edges and the cell movement in 3D. With these assumptions, we are able to qualitatively predict some features such as cell movement tendencies, traction forces and cell speeds in several substrates with different stiffnesses and under different mechanical constraints.

The premise of this paper is that a better understanding of all these features provides new possibilities to guide and regulate tissue regeneration, and is therefore useful for the design of new biomaterial scaffolds aiming at optimizing mechanical conditions to control cell migration for tissue engineering applications or medical device designs.

\section{Model formulation}

In this work, we mainly focus on the mechanical interaction of an individual cell with the ECM/substrate. We compute the migration of a single cell to isolate the mechanical inputs from other possible intercellular interactions. Chemical or other factors are not taken into account, thereby, the cell movement is only regulated by the mechanical properties of the matrix and the cell-matrix interactions.

When a cell migrates, complex-coupled and cyclic mechanisms are activated regulating its movement, which includes polarization, protrusion and adhesion, contraction of the cell body and retraction of the rear [33, 45, 46]. The cell embedded within the gel extends filopodia and/or lamellipodia possibly to sense the surrounding mechanical conditions. Contractile forces are exerted to evaluate the substrate stiffness, and consequently the substrates (and the cell) are stressed and strained [47]. According to this, the cell's CSK adapts, and the cell becomes directionally polarized. More focal adhesions develop at the front than at the rear. Detachment of rear adhesions leads to the imbalance of traction forces that they can support, subsequently resulting in the contraction and forward movement of the cell [6].

In this model we assume that these mechanisms can be simplified into three fundamental ones: mechanosensing, CSK adaptation and cell movement. Although they occur simultaneously, for simplicity, we consider them as independent, but interrelated mechanisms. In fact, we couple these three different mechanisms assuming that all of them are regulated by the contraction stress exerted by the cell on the ECM/substrate during the mechano-sensing phase.

\section{Mechano-sensing mechanism}

The CSK is a dynamic structure that maintains cell shape [48], protects it and plays an important role in different processes such as cell division [49], intracellular transport [50] or cell locomotion [51]. The behavior of this structure is complex and various approaches have been adopted to model its interesting rheological [52-55] and contractile properties [15, 56, 57]. In this work, we propose a simplified model based on a spring-like structure with contractile actuators to model the whole body of the cell (see figure 1). The cellular elements responsible for the cell mechanics behavior considered here are [38] the actin bundles $\left(K_{\text {act }}\right)$, the actomyosin contractile apparatus (AM) and the passive mechanical stiffness of the rest of the cell whose main contribution comes from the cytoskeleton actin microfilaments and the membrane $\left(K_{\text {pas }}\right)$. The CSK 

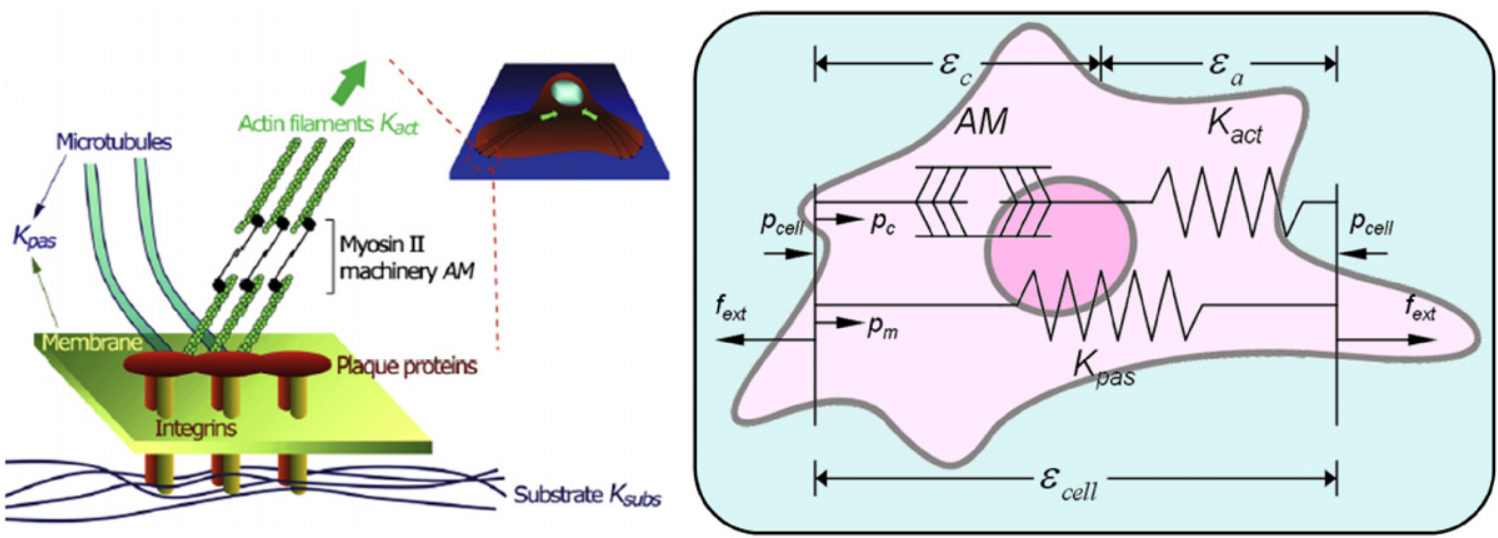

Figure 1. Mechano-sensing model of the cell following classical Hill's functional model of the muscle [38, 58, 59]. Schematic diagram of the relevant mechanical constituents and the corresponding mechanical model. Actin bundles are modeled as a spring (with stiffness $K_{\text {act }}$ ) in series with the AM contractile system, whose stress $\left(p_{c}\right)$ depends on its strain $\left(\varepsilon_{c}\right)$. These components act in parallel with the spring modeled passive elements of the cell body (microtubules, non-myosin associated actin, and the membrane $\left.K_{\text {pas }}\right)$. The cell strain $\left(\varepsilon_{\text {cell }}\right)$ divides into the strain of the actin bundles $\left(\varepsilon_{a}\right)$ and the strain of the AM motors $\left(\varepsilon_{c}\right)$. All the parameters are listed in table 1.

is linked with the ECM/substrate through focal adhesions and transmembrane integrins that are assumed perfectly rigid during the mechano-sensing phase in our model.

The stress effectively transmitted by the cell to the ECM $\left(p_{\text {cell }}\right)$ depends on the cell strain $\left(\varepsilon_{\text {cell }}\right)$. This strain can be decomposed into two parts: the strain in the actin bundles $\left(\varepsilon_{a}\right)$ and the strain in the contractile AM system $\left(\varepsilon_{c}\right)$. Therefore, we obtain

$$
\varepsilon_{\mathrm{cell}}=\varepsilon_{a}+\varepsilon_{c}
$$

Since the actin bundles are modeled as a spring with a stiffness $K_{\text {act }}, \varepsilon_{a}$ can be expressed as

$$
\varepsilon_{a}=\frac{p_{c}}{K_{\mathrm{act}}} .
$$

The stress that the cell effectively transmits to the $\mathrm{ECM} /$ substrate corresponds to the sum of the contribution of the active actin-myosin component and the stress absorbed by the passive elements ( $p_{c}$ and $p_{m}$ respectively):

$$
p_{\text {cell }}\left(\varepsilon_{\text {cell }}\right)=p_{c}+p_{m}=p_{c}\left(\varepsilon_{c}\right)+K_{\text {pas }} \varepsilon_{\text {cell }} .
$$

The active stress contribution of the actin-myosin motors $\left(p_{c}\right)$ is related to the extension/contraction (overlap) between the actin-myosin filaments $\left(\varepsilon_{c}\right)$ [59]. Here, we assume the following form:

$$
p_{c}\left(\varepsilon_{c}\right)= \begin{cases}0 & \varepsilon_{c}<\varepsilon_{\min } \\ \frac{p_{\max }}{-\varepsilon_{\min }}\left(\varepsilon_{c}-\varepsilon_{\min }\right) & \varepsilon_{\min }<\varepsilon_{c}<0 \\ \frac{p_{\max }}{\varepsilon_{\max }}\left(\varepsilon_{\max }-\varepsilon_{c}\right) & 0<\varepsilon_{c}<\varepsilon_{\max } \\ 0 & \varepsilon_{\max }<\varepsilon_{c} .\end{cases}
$$

This function is plotted in figure 2 where four different zones can be distinguished as a function of the value of $\left(\varepsilon_{c}\right)$.

Without external loads, the mechanical equilibrium is governed by the AM contractile system that contracts the cell body (zone 2: $\varepsilon_{\min }<\varepsilon_{c}<0$ ) and causes tension on the cell surroundings. With external compression, $\varepsilon_{c}<\varepsilon_{\min }$, the $\mathrm{AM}$ contractile system is not able to exert contraction forces

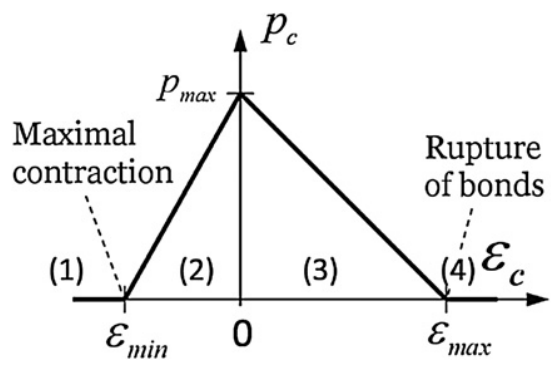

Figure 2. Dependence of the contractile AM stress $\left(p_{c}\right)$ on the AM overlap $\left(\varepsilon_{c}\right) \cdot p_{\max }$ stands for the maximum contractile stress that the AM machinery is able to exert. Zone 1: passive behavior, external loads compress the cell; the AM system is too compressed to exert any active force. Zone 2: contraction, the natural state without external loads, the cell exerts contractive forces to sense its surroundings. Zone 3: tension, the cell is being stretched by external loads but still contracts itself against those forces. Zone 4: passive behavior, external loads stretch the cell, the AM system is too stretched to exert any active force. Adapted from [38].

(zone 1). However, when there are external loads causing cell extension (zones 3 and 4), cell contraction is compensated decreasing the AM contractile action until reaching $\varepsilon_{\max }$ where its force contribution equals 0 .

In summary, combining equations (1), (2) and (4), equation (3) can be rewritten and the magnitude of $p_{\text {cell }}$ can be expressed as follows:

$$
\begin{aligned}
& p_{\text {cell }}\left(\varepsilon_{\text {cell }}\right)= \\
& \begin{cases}K_{\text {pas }} \varepsilon_{\text {cell }} & \varepsilon_{\text {cell }}<\varepsilon_{\text {min }} \\
\frac{K_{\text {act }} p_{\max }}{K_{\text {act }} \varepsilon_{\min }-p_{\max }}\left(\varepsilon_{\text {min }}-\varepsilon_{\text {cell }}\right)+K_{\text {pas }} \varepsilon_{\text {cell }} & \varepsilon_{\text {min }}<\varepsilon_{\text {cell }}<\left(p_{\text {max }} / K_{\text {act }}\right) \\
\frac{K_{\text {act }} p_{\max }}{K_{\text {act }} \varepsilon_{\max }-p_{\max }}\left(\varepsilon_{\text {max }}-\varepsilon_{\text {cell }}\right)+K_{\text {pas }} \varepsilon_{\text {cell }} & \left(p_{\text {max }} / K_{\text {act }}\right)<\varepsilon_{\text {cell }}<\varepsilon_{\max } \\
K_{\text {pas }} \varepsilon_{\text {cell }} & \varepsilon_{\text {max }}<\varepsilon_{\text {cell }} .\end{cases}
\end{aligned}
$$

Although the description thus far has been in terms of a scalar stress, we now extend this to three dimensions using 
$p_{\text {cell }}$ to compute an effective stress tensor $\boldsymbol{\sigma}_{\text {cell }}$. We assume that the cell occupies a spherical space, with constant shape and volume. However, the cell is exerting anisotropic forces on its immediate surroundings depending on the temporal evolution of the CSK polarization. Considering this mechanosensing model, we assume that the total cell stress tensor $\sigma_{\text {cell }}$ is a function of the total cell strain tensor $\varepsilon_{\text {cell }}$ and consists of two terms related to the orientation of the CSK. One term is isotropic and dependent on the volumetric strain $\left(\theta_{\text {cell }}\right)$ (trace of the cell strain tensor $\left.\varepsilon_{\text {cell }}\right)$ considering that the cell body contracts in all directions. The other is anisotropic depending on the direction of the CSK polarization $\left(\boldsymbol{d}_{\mathrm{pol}}\right)$, and the longitudinal deformation in the polarization direction $\left(\varepsilon_{\text {cell }}=\boldsymbol{d}_{\mathrm{pol}}^{T} \cdot \varepsilon_{\mathrm{cell}} \cdot \boldsymbol{d}_{\mathrm{pol}}\right)$. Hence, we propose the following expression to define the stress behavior of the cell:

$$
\boldsymbol{\sigma}_{\text {cell }}=p_{\text {cell }}\left(\varepsilon_{\text {cell }}\right) \boldsymbol{d}_{\text {pol }} \otimes \boldsymbol{d}_{\text {pol }}+p_{\text {cell }}\left(\theta_{\text {cell }}\right) \boldsymbol{I},
$$

where $\boldsymbol{I}$ is the identity second-order tensor and $\boldsymbol{d}_{\mathrm{pol}}$ is the direction of polarization of the CSK which is described in the following subsection.

The global mechanical equilibrium has to be fulfilled in the cell body and in the substrate, which is modeled as a linear elastic solid to a first approximation. The ECM or substrate stress tensor $\left(\sigma_{\text {subs }}\right)$ must be in equilibrium with the external forces applied $\left(\boldsymbol{f}_{\text {ext }}\right)$ e.g. a needle inserted in the matrix exerting pulling or pushing forces:

$$
\begin{gathered}
\nabla\left(\boldsymbol{\sigma}_{\text {cell }}\right)=0 \quad \text { in } \Omega_{\text {cell }} \\
\nabla\left(\boldsymbol{\sigma}_{\text {subs }}\right)=\boldsymbol{f}_{\text {ext }} \text { in } \Omega_{\text {subs }} .
\end{gathered}
$$

To solve these mechanical equilibrium equations, we use the finite element method (FEM) (details of this analysis are given in section 3 ).

\section{CSK adaptation}

Here, we hypothesize that the mechano-sensing mechanism permits the cell to detect the principal directions $\left(\boldsymbol{d}_{\varepsilon}\right)$ of the cell strain tensor $\varepsilon_{\text {cell }}$, and that the CSK is reoriented according to them. Initially, we assume the cell to be an isotropic and homogeneous body embedded in the ECM. Consistent with previous experimental observations [20], we assume that the active AM fibers develop preferentially parallel to the direction of lower principal strain or higher principal stress.

Hence, we assume that the cell aligns gradually with the closer principal strain direction (see figure 3 ) as follows:

$$
\Delta \boldsymbol{d}_{\mathrm{pol}}=\frac{\mathrm{d} \boldsymbol{d}_{\mathrm{pol}}}{\mathrm{d} t} \Delta t=\kappa\left(\boldsymbol{d}_{\mathrm{pol}}^{i} \times\left(\boldsymbol{d}_{\varepsilon} \times \boldsymbol{d}_{\mathrm{pol}}^{i}\right)\right) \Delta t,
$$

where the index $i$ denotes the time step and $\boldsymbol{d}_{\varepsilon}$ is the principal strain direction, which forms the lower angle $(\alpha)$ with the previous polarization direction $\boldsymbol{d}_{\mathrm{pol}}^{i}$. The symbol $\kappa$ is the constant of reorientation $\left(\mathrm{min}^{-1}\right)$ and determines how fast the vectors align. Once this direction is defined, it is updated as follows:

$$
d_{\mathrm{pol}}^{i+1}=d_{\mathrm{pol}}^{i}+\Delta \boldsymbol{d}_{\mathrm{pol}}
$$

Note that at the end of each time step, $\boldsymbol{d}_{\mathrm{pol}}^{i+1}$ is normalized, becoming the unitary vector $\boldsymbol{d}_{\mathrm{pol}}^{i}$ for the next time step. We

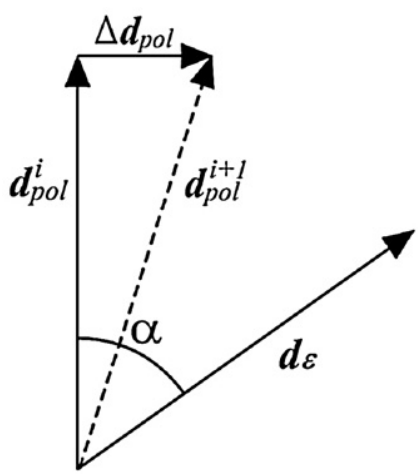

Figure 3. Schematic representation of CSK reorientation. The direction of polarization of the current time step $\left(\boldsymbol{d}_{\mathrm{pol}}^{i}\right)$ rotates toward the nearest principal strain direction $\left(\boldsymbol{d}_{\varepsilon}\right)$ resulting in the new polarization direction $\left(\boldsymbol{d}_{\mathrm{pol}}^{i+1}\right)$. The initial angle between $\boldsymbol{d}_{\mathrm{pol}}$ and $\boldsymbol{d}_{\varepsilon}$ is denoted by $\alpha$, and $\Delta \boldsymbol{d}_{\mathrm{pol}}$ indicates the change in $\boldsymbol{d}_{\mathrm{pol}}$ direction per time step. Note that at the end of each time step, $\boldsymbol{d}_{\mathrm{pol}}^{i+1}$ is normalized.

assume $\kappa$ to be $1 / 30 \mathrm{~min}^{-1}$, which means that when $\boldsymbol{d}_{\varepsilon}$ and $\boldsymbol{d}_{\text {pol }}$ are perpendicular, the cell is able to orientate its CSK $\pi / 4$ degrees in a single time step to align with $\boldsymbol{d}_{\varepsilon}$. It has been observed in experiments [60-62] that cells remodel their cytoskeleton on a timescale of tens of minutes to hours. This timescale has been also used in other modeling works [63].

\section{Migration}

The last mechanism to be modeled is the cell movement as dictated by an equilibrium of forces on the cell centroid [33]. It is important to clarify that we are considering this mechanism totally distinct from the mechano-sensing one, although they are obviously interdependent. Thus, the stress equilibrium (equation (7)) is not affected by the subsequent formulation, since in our model, migration occurs sequentially following mechano-sensing and CSK remodeling. Nevertheless, we assume that they are related through $p_{\text {cell }}\left(\varepsilon_{\text {cell }}\right)$.

If we focus on the equilibrium of forces for each single cell, we consider three distinct types of independent forces acting on the cell, which define its movement [33] according to

$$
\boldsymbol{F}_{\text {tot }}=\boldsymbol{F}_{\text {prot }}+\boldsymbol{F}_{\text {drag }}+\boldsymbol{F}_{\text {trac }}=\mathbf{0} .
$$

The protrusive force, $\boldsymbol{F}_{\text {prot }}$, is needed to extend membrane processes and is independent of myosin motors. It arises from actin polymerization and cell-matrix interactions and introduces stochastic behavior to the model [33]. It is calculated as a vector with random direction with magnitude proportional to $p_{\text {cell }}\left(\varepsilon_{\text {cell }}\right)$. This implies that the direction of cell migration is always random in the absence of any effect of chemotaxis, haptotaxis or durotaxis.

The second force, $\boldsymbol{F}_{\text {drag }}$, represents the resistance to movement, which is proportional to the cell speed $\left(\boldsymbol{v}_{\text {cell }}\right)$ :

$$
\boldsymbol{F}_{\text {drag }}=\eta \boldsymbol{v}_{\text {cell }},
$$

where $\eta$ is an effective viscosity that reflects the sum of all dissipation effects including viscous friction as well as the energy dissipated by the rupture of bonds under tension. 
Table 1. Major parameters used in the model.

\begin{tabular}{|c|c|c|c|}
\hline Symbol & Variable & Value & Reference \\
\hline$K_{\text {pas }}$ & Passive cell stiffness & $0.001(\mathrm{MPa})$ & {$[66]$} \\
\hline$K_{\text {act }}$ & Actin stiffness & $0.01(\mathrm{MPa})$ & [66] \\
\hline$\varepsilon_{\min }$ & $\begin{array}{l}\text { Minimum strain } \\
\text { (maximum overlap) }\end{array}$ & -0.4 & [38] \\
\hline$\varepsilon_{\max }$ & $\begin{array}{l}\text { Maximum strain } \\
\text { (minimum overlap) }\end{array}$ & 0.4 & {$[38]$} \\
\hline$p_{\max }$ & $\begin{array}{l}\text { Maximum stress } \\
\text { exerted by the AM } \\
\text { system }\end{array}$ & $2.5(\mathrm{kPa})$ & {$[67]$} \\
\hline$\kappa$ & Reorientation constant & $0.0333\left(\mathrm{~min}^{-1}\right)$ & $\mathrm{a}$ \\
\hline$K_{\text {subs }}$ & Substrate stiffness & $0.001-0.5(\mathrm{MPa})$ & {$[64]$} \\
\hline$c_{\mathrm{vis}}$ & Viscosity slope & $0.4(\mu \mathrm{m} \min )$ & {$[64]^{\mathrm{b}}$} \\
\hline$\eta_{0}$ & Viscosity constant & $0.07\left(\mu \mathrm{N} \min \mu \mathrm{m}^{-1}\right)$ & {$[64]^{\mathrm{b}}$} \\
\hline$k_{B}$ & $\begin{array}{l}\text { Binding constant at the } \\
\text { cell's back }\end{array}$ & $10^{8}\left(\mathrm{M}^{-1}\right)$ & {$[33,35]$} \\
\hline$k_{F}$ & $\begin{array}{l}\text { Binding constant at the } \\
\text { cell's front }\end{array}$ & $10^{8}\left(\mathrm{M}^{-1}\right)$ & {$[33,35]$} \\
\hline$\left[n_{B}\right]$ & $\begin{array}{l}\text { Ratio of receptors at } \\
\text { the cell's back }\end{array}$ & 0.05 & {$[35,65]$} \\
\hline$\left[n_{F}\right]$ & $\begin{array}{l}\text { Ratio of receptors at } \\
\text { the cell's front }\end{array}$ & 0.95 & {$[35,65]$} \\
\hline$\left[L_{B}\right]$ & Back ligand density & $10^{-8}(\mathrm{M})$ & {$[35]$} \\
\hline$\left[L_{F}\right]$ & Front ligand density & $10^{-8}(\mathrm{M})$ & {$[35]$} \\
\hline$a_{a}$ & $\begin{array}{l}\text { Effective area of } \\
\text { traction }\end{array}$ & $55\left(\mu \mathrm{m}^{2}\right)$ & a \\
\hline$\Delta t$ & Time increment & $30(\min )$ & [33] \\
\hline$E_{1}$ & $\begin{array}{l}\text { Young's modulus of } \\
\text { the substrate }\end{array}$ & $0.001(\mathrm{MPa})$ & [64] \\
\hline$E_{2}$ & $\begin{array}{l}\text { Young's modulus of } \\
\text { the substrate }\end{array}$ & $0.04(\mathrm{MPa})$ & {$[64]$} \\
\hline$v$ & $\begin{array}{l}\text { Poisson's ratio of the } \\
\text { substrate }\end{array}$ & 0.3 & {$[19,20]$} \\
\hline
\end{tabular}

a Estimated parameters.

b Parameters derived from the referenced manuscript.

Based on the approach proposed in [64], we assume this viscosity coefficient to be a linearly increasing function of the substrate stiffness $\left(K_{\text {subs }}\right)$, where $c_{\text {vis }}(\mu \mathrm{m}$ min) is its slope. We have slightly modified this function from that used in [64], incorporating a minimum value of viscosity $\eta_{0}\left(\mu \mathrm{N} \mathrm{min} \mu \mathrm{m}^{-1}\right)$ (see table 1):

$$
\eta=\eta_{0}+c_{\text {vis }} K_{\text {subs }} \text {. }
$$

The third force, $\boldsymbol{F}_{\text {trac }}$, is the traction force exerted by the cell in order to move. It has two contributions, the traction force at the front part of the cell $\left(\boldsymbol{F}_{\operatorname{trac} F}\right)$ and the traction force at the rear $\left(\boldsymbol{F}_{\operatorname{trac} B}\right)$. We assume that the definition of the front and the rear parts of the cell is intrinsic to the mechano-sensing mechanism presented here. When the cell contracts its body, its centroid displaces toward the more constrained side following the imposed boundary conditions or the stiffness variations, establishing in this way the 'front'. Since focal adhesions tend to exhibit higher density at the front, the rear adhesions experience more stress per bond and tend to detach. Even though this behavior is highly dynamic, we assume for simplicity that there is a constant difference in strength between the front and back receptors. To reflect this, similar to [33], we introduce a dimensionless 'adhesivity' $(\beta)$ at the front and back parts of the cell, which is assumed proportional to the ratio of cell receptors $\left(n_{F}, n_{B}\right)$, the ligand concentrations $\left(\left[L_{F}\right],\left[L_{B}\right]\right)$ and the binding constants for the binding of integrins of the cell to the ligands in the $\operatorname{ECM}\left(k_{F}, k_{B}\right)$ :

$$
\begin{aligned}
& \beta_{F}=k_{F} n_{F}\left[L_{F}\right] \\
& \beta_{B}=k_{B} n_{B}\left[L_{B}\right] .
\end{aligned}
$$

In the current model, we assume that as the cell polarizes and adaptates, integrins are distributed asymmetrically on the cell surface $\left(n_{F}>n_{B}\right)$. During migration, the majority of integrins shift to the leading edge of the cell [35, 65], so we consider that $95 \%$ of the total number of receptors are localized at the front. Also for simplicity, we assume $k_{F}=k_{B}$ and $\left[L_{F}\right]=\left[L_{B}\right]$, considering that the ligand density is spatially uniform throughout the matrix, at least initially. It is important to note that matrix metalloproteinases produced by migrating cells can alter the ligand density in the extracellular matrix. Furthermore, cells can also synthesize new matrix components with associated adhesion receptor ligands and can cause deformations in the matrix due to cell contraction. The dynamics of these processes may be important for modulation of migration through the matrix, but in this first version of the model we have not included their effects. Under these assumptions, the traction forces magnitude, depends upon the cell stress $p_{\text {cell }}$ and the area over which it is applied $\left(a_{a}\right)$. Cells transmit mechanical forces to the ECM through focal adhesions, which dynamically assemble and disassemble during cell migration. However, both the composition and the morphology of focal adhesions change during cell migration but the mechanism is complex and still poorly understood. Establishing a constant parameter to simulate the contact area is a first approach to this problem. Therefore, $a_{a}$ was fitted to obtain contractile forces and cell speeds similar to those observed in experiments performed with fibroblasts [28, 33]. With all this, traction forces are exerted in the direction of polarization $\left(\boldsymbol{d}_{\mathrm{pol}}\right)$ and can be expressed as

$$
\begin{gathered}
\boldsymbol{F}_{\text {trac } F}=\beta_{F} p_{\text {cell }} a_{a} \boldsymbol{d}_{\mathrm{pol}} \\
\boldsymbol{F}_{\text {trac } B}=\beta_{B} p_{\text {cell }} a_{a} \boldsymbol{d}_{\mathrm{pol}} .
\end{gathered}
$$

The resultant traction force $\left(\boldsymbol{F}_{\text {trac }}\right)$ is the difference of the traction forces at the front and the rear:

$$
\boldsymbol{F}_{\text {trac }}=\boldsymbol{F}_{\text {trac } F}-\boldsymbol{F}_{\text {trac } B}=\left(\beta_{F}-\beta_{B}\right) p_{\text {cell }} a_{a} \boldsymbol{d}_{\text {pol }} .
$$

Cell speed can be therefore calculated from equations (10) and (11) and the new cell position can be determined:

$$
\boldsymbol{v}_{\mathrm{cell}}=\left(\boldsymbol{F}_{\mathrm{prot}}+\left(\beta_{F}-\beta_{B}\right) p_{\mathrm{cell}} a_{a} \boldsymbol{d}_{\mathrm{pol}}\right) \eta^{-1} \text {. }
$$

\section{Numerical implementation}

This model has been implemented using three distinct, sequential processes at each time step (mechano-sensing, polarization and migration), following the loop shown in figure 4. This simplified analysis in three different computations aims to replicate the most relevant mechanisms used by individual cells to migrate. As initial conditions we assume that both the substrate and the cell are completely 


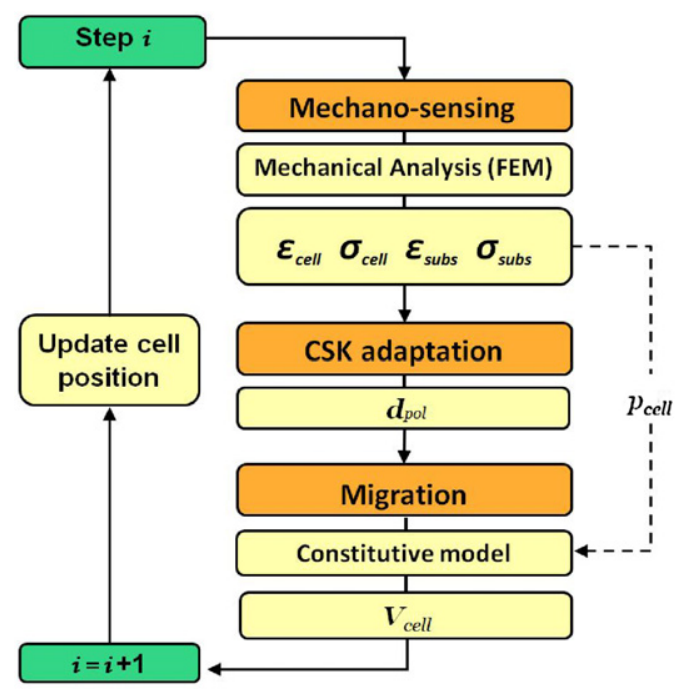

Figure 4. Computational algorithm of each step. First the cell exerts contraction forces on the ECM in order to sense its surroundings (mechano-sensing). The stress and strain produced in the ECM regulate the cell polarization (CSK adaptation). After that, the traction forces exerted to move are computed to determine the cell speed (migration). When a new position is computed, this loop is repeated.

unloaded; thus, the displacement, strain and stress fields are zero in the whole domain. We consider that the cell is not polarized and we specify its initial position. In addition, at the beginning of each step of analysis, the stress/strain fields are assumed to be zero in both the cell body and the substrate. At the end of each time step, the location and the polarization of the cell are updated.

Now we briefly describe these three analyses that define one time step. First, the mechano-sensing analysis provides a calculation of the strain field in the ECM and the cell strain due to the cell contraction. To solve this mechanical problem, we use the FEM through a commercial software package (SimuliaABAQUS FEA 6.9) using user subroutines to incorporate the active behavior of the cell. For the implementation, we model the cell body as a single hexahedron element. This simplification highly facilitates the computation of the mechanical problem since it allows using regular hexahedrons (element type: C3D8) for both ECM and cell $(20 \times 20 \times$ $20 \mu \mathrm{m}$ shape). To start the simulation, the cell is initially placed in a specific element and exerts contraction forces to sense its surroundings (equation (7)). In this first step, the contraction is isotropic as the cell is not yet polarized. The element is compressed in all directions and its neighbors are under tension. These forces produce displacements, strains ( $\varepsilon_{\text {cell }}$ and $\left.\varepsilon_{\text {subs }}\right)$ and stresses $\left(\sigma_{\text {cell }}\right.$ and $\left.\sigma_{\text {subs }}\right)$ on the cell and the substrate, respectively.

The second analysis corresponds to the cell polarization or CSK adaptation. It consists of an algorithm to evaluate the orientation of the cell body. Therefore, through the nodal displacements, the tensor $\varepsilon_{\text {cell }}$ and its principal directions $\left(\boldsymbol{d}_{\varepsilon}\right)$ are evaluated, as well as $p_{\text {cell }}$ and all the related variables. For simplification, we assume that the cell reorients in each step with one of the principal strain directions. In the first step, $\boldsymbol{d}_{\text {pol }}$ is still undefined, so initially the direction of minimum contraction $\left(\boldsymbol{d}_{\varepsilon 1}\right)$ is selected. In successive steps, the direction is not always the first one, but closer to the polarization direction as was previously described. This means that the cell prefers to migrate in the direction in which it is already oriented; however, this does not imply that the cell moves in a unidirectional manner.

Thirdly, after sensing and reorientation, migration is computed taking into account the equilibrium of forces (see equation (10)), evaluating cell speed from equation (16) and updating the new position of the cell. In all the examples, the total time analyzed is $9 \mathrm{~h}$ with a time increment of $30 \mathrm{~min}$.

\section{Results}

\section{Parameter sensitivity}

The model has the capability of capturing a wide variety of behaviors by appropriate selection of the model parameters. A sensitivity analysis is performed in order to illustrate some types of behavior that can be produced and also to better understand the relative importance of the major parameters. All the reference values used in all the simulations are in table 1 .

Actin stiffness. The actin stiffness $\left(K_{\text {act }}\right)$ is a critical factor which determines the magnitude of the forces $\left(p_{\text {cell }}\right)$ exerted during mechano-sensing. By virtue of the model construction, it also determines the magnitude of traction forces and therefore the velocity (see figures $5(A)$ and $(B)$ ). It is interesting to note that the dependence of cell speed on substrate stiffness is bi-modal, having a peak at a substrate stiffness of about 20-30 kPa. The forces increase with stiffness until they saturate. Increasing the value of $K_{\text {act }}$ leads to lower AM overlap, reducing contraction and causing higher forces with the same substrate stiffness. Therefore cell speed increases accordingly. Interestingly, the value of $K_{\text {pas }}$, although also important, plays a significant role only when its value is similar to the substrate stiffness (data not shown).

Viscosity. As described in equation (12), the viscosity is assumed to increase linearly with substrate stiffness, and its value strongly affects cell behavior. In fact, viscosity saturates, but it happens outside the rigidity range of this study [22]. The speed is very sensitive to the value of $\eta_{0}$ for the range of stiffness tested, since it defines the minimum viscosity in softer substrates. If this factor is decreased, the cell can reach higher velocities in softer substrates (see figure $6(A)$ ). Nevertheless, the slope $c_{\text {vis }}$ also significatively affects the velocity, specially at high stiffness. This effect, as mentioned before, is due to the saturation of forces at high stiffness. If this factor is decreased, the velocity increases and the point of maximum speed is displaced to a higher substrate stiffness (see figure 6(B)). 

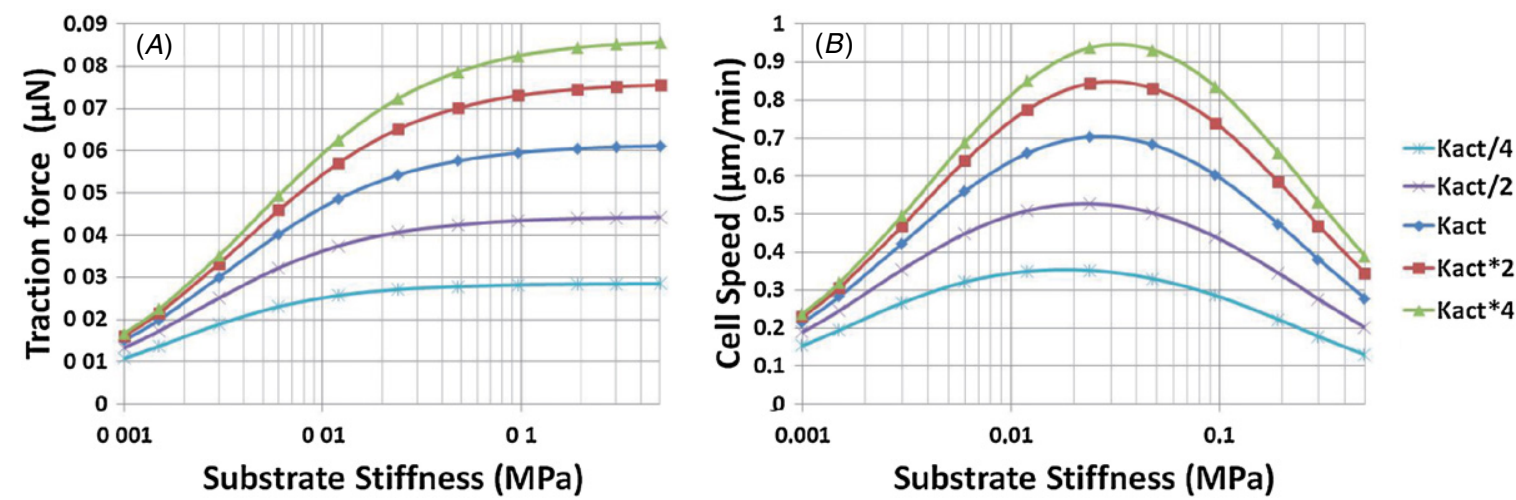

Figure 5. Effect of substrate stiffness and cell actin stiffness on traction forces and cell speed. $(A)$ The actin stiffness of the cell $\left(K_{\text {act }}\right)$ determines the magnitude of the forces exerted during mechano-sensing $\left(p_{\text {cell }}\right)$, therefore affecting cell migration. Lower values of $K_{\text {act }}$ lead to a weaker cell traction. In addition, traction forces are higher for stiffer substrates. $(B)$ Cell speed depends on traction forces and viscosity. Traction forces decrease for lower values of $K_{\text {act }}$ and, consequently, low values of $K_{\text {act }}$ lead to slower cell motion over the entire range of substrate stiffness in comparison with the reference value.
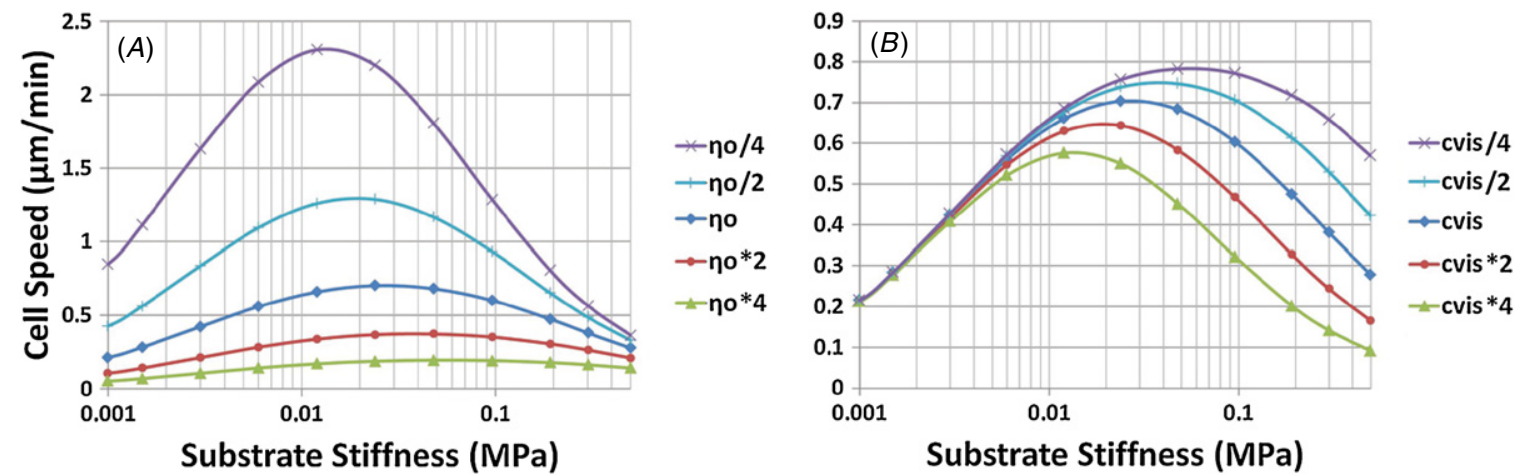

Figure 6. Effect of substrate stiffness and substrate viscosity on the cell speed. $(A),(B)$ The dependence of cell speed on substrate stiffness is bi-modal, having a peak which depends on the viscosity. Two parameters define substrate viscosity: $\eta_{0}$ and $c_{\text {vis }}$. If these factors are decreased, the cell speed increases. (A) Lower values of $\eta_{0}$ lead to higher speeds in softer substrates. $(B)$ Lower values of $c_{\text {vis }}$ lead to higher speeds, especially in stiffer substrates.

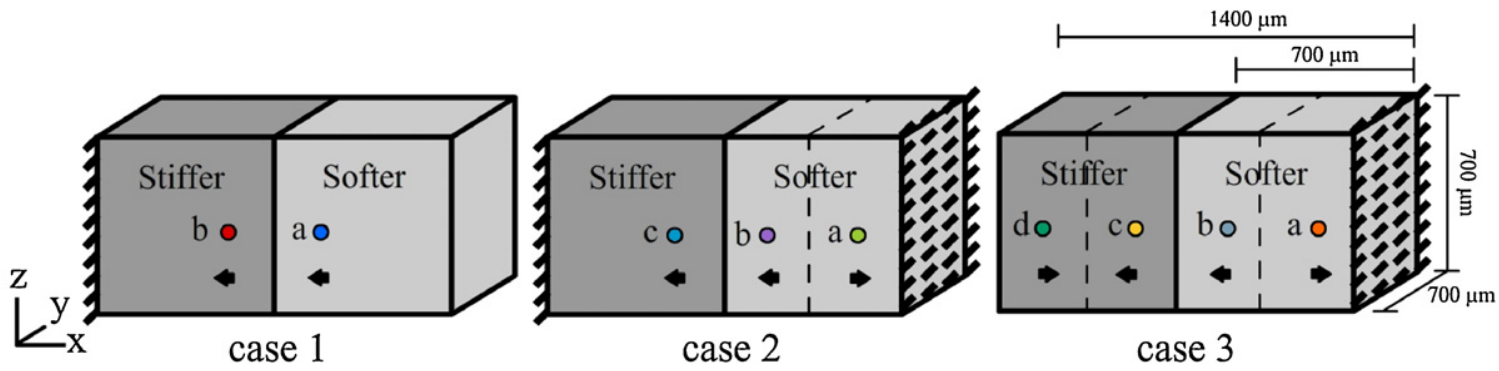

Figure 7. The three cases studied. The size of the computational domain is $1400 \times 700 \times 700 \mu \mathrm{m}$. Black arrows represent the direction of migration. Dotted lines represent zones where a change in the migration direction is observed. Circles in each case represent schematically the initial cell position for each subcase. For quantitative distances see figure 8. Case 1. The stiffer side is constrained (fixed nodes on the left surface) and the softer side is free of external loads (on the right surface). The remaining four surfaces are also free of external loads. Case 2. Both sides are constrained (fixed nodes on left and right surfaces). The remaining four surfaces are free of external loads. Case 3. The stiffer side is free of loads (on the left surface), whereas the softer side is constrained (fixed nodes on the right surface). The remaining four surfaces are also free of external loads.

\section{Sample calculation}

We simulate a 3D ECM/substrate, which consists of a rectangular cuboid of the following dimensions: $1400 \times$ $700 \times 700 \mu \mathrm{m}$, with two different rigidities $\left(E_{2}=0.04 \mathrm{MPa}\right.$, $E_{1}=0.001 \mathrm{MPa}$ ) under different boundary conditions listed below for each of the three examples analyzed here (figure 7).
Case 1. The stiffer side is constrained (fixed nodes on the left surface) and the softer side is free of external loads (on the right surface). The remaining four surfaces are also free of external loads.

Case 2. Both sides are constrained (fixed nodes on left and right surfaces). The remaining four surfaces are free of external loads. 


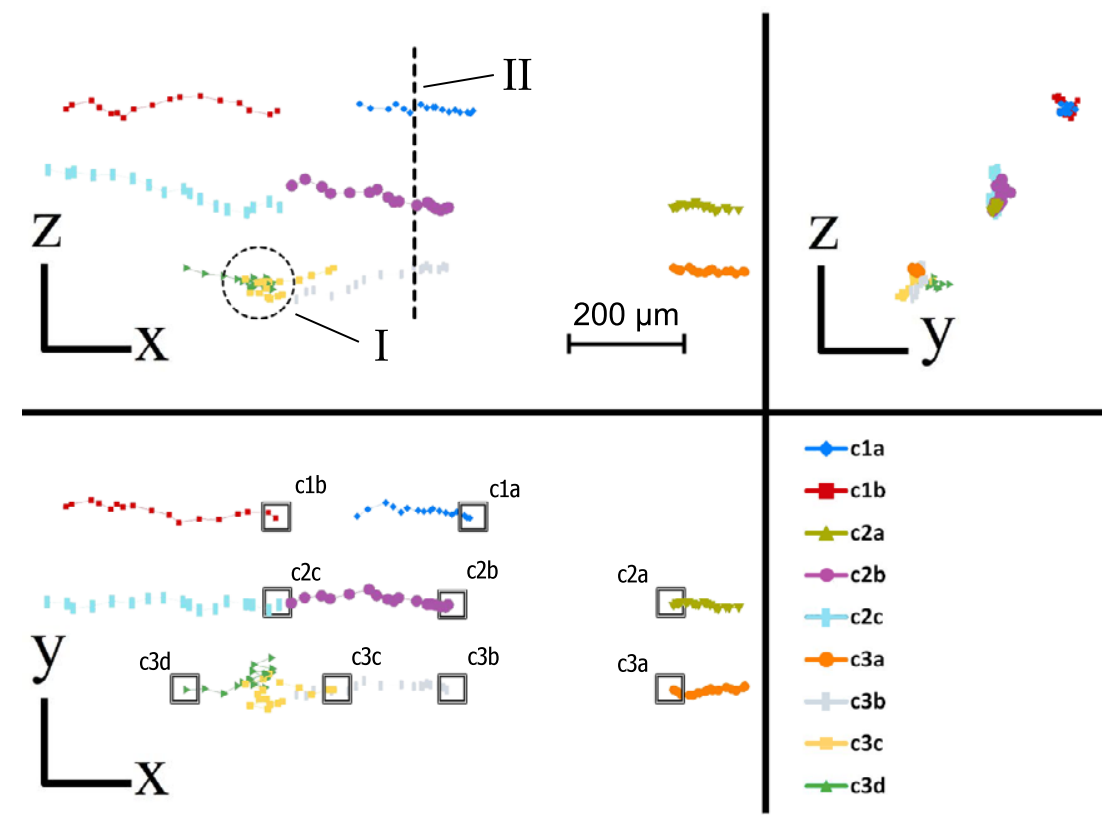

Figure 8. Migration patterns in 3D for the sample calculation. The boundary conditions used (free or fixed nodes on the $y-z$ planes on the sides) and changes in Young's modulus of the substrate mainly affect the horizontal migration ( $x$-direction), although migration also occurs in the $y$ - and -directions, due to random forces. Nevertheless, in the studied conditions, movement changes in the $y-z$ plane (top right) are lower in comparison with migration in either the $x-y$ (bottom left) or $x-z$ (top left) planes. The initial position of each case is highlighted with a square and the corresponding label. II denotes the interface separating the regions of different stiffnesses. Note that in all simulations, the cell starts at the same $y-z$ point, but are plotted displaced to identify clearly the different cases. In the first case (c1a, clb), no matter where the cell is initially placed, it moves to the left toward the constraint where Young's modulus is higher. In the second one, another constraint (fixed nodes) is placed on the softer side, and consequently a zone where the cell changes its migration direction appears. If the cell is placed close enough to this constraint (c2a), it moves toward it. In other cases (c2b, c2c), it migrates to the left as in the first case. In the third case, the constraint on the stiffer side is removed. This causes a third zone to appear. As well as in previous cases, a cell placed in the left zone, near the right constraint (c3a) moves toward it and a cell placed further away in the intermediate zone (c3b) moves toward the stiffer substrate. However, if it migrates far enough to reach the left zone (c3c), it becomes trapped near this interface (I), since the tendency of the cell in the left zone is to move toward right (c3d). For each cell, this change in its migration pattern, always happens at the same $x$-coordinate, but at different $y$ - and $z$-coordinates due to the randomness of the cell movement.

Case 3. The stiffer side is free of loads (on the left surface), whereas the softer side is constrained (fixed nodes on the right surface). The remaining four surfaces are also free of external loads.

We use a regular mesh of 85750 hexahedron elements (C3D8). Simulated time is $9 \mathrm{~h}$, whereas the computational time is $30 \mathrm{~min}$.

Although only some results corresponding to different initial positions in each case are shown (subcases), many simulations have been performed, finding similar and consistent patterns. At least ten repetitions per subcase were tested. The computed trajectories of migration were all different due to the stochastic behavior; however, the general trend was consistent for each subcase. Hence, for clarity, only one of the examples for each subcase is plotted in figure 8. As the boundary conditions change along the $x$-axis, the principal results are discussed focusing on migration in the $x$-direction. Note that all the subcases are referred as c-casenumber-letter.

In the first case, no matter where the cell is initially placed, either in the softer side (c1a) or the stiffer side (c1b), since it always moves toward the constrained side, which also has the highest Young's modulus $\left(E_{2}\right)$. The cell never migrates from the stiffer side to the softer one (see figure 8 ).
Note that the randomness seen in the trajectories causes the cell to deviate from a straight line, and move out of the $x-$ $y$ plane. These computational results are consistent with experiments [9], where they found that cells tend to move from a soft substrate to a stiffer one, but not in the opposite direction.

In the second case, as the soft side is also constrained, there exists a zone (dotted line in the figures) where the cell changes its migration direction. A cell placed close enough to the soft side constraint (c2a) moves toward that boundary. In other cases (cells placed further from the boundary), the tendency is to move toward the left constraint, whether the cell is initially on the softer $(c 2 b)$ or stiffer side (c2c) (see figure 8).

In the third example, three zones can be distinguished (separated by dotted lines). From right to left, a cell placed in the right zone, near the constraint (c3a), migrates directly toward it as in the previous case. A cell placed in the intermediate zone, either on the softer side (c3b) or the stiffer side $(\mathrm{c} 3 \mathrm{c})$, moves to the left. If the cell reaches the left zone (c3c), it stops its advance and moves backward. Once again in the intermediate zone, the cell migrates to the left, crosses to the left zone and moves backward, repeating this process randomly, but indefinitely. Thus, in a zone with no differences 
in mechanical properties and in the absence of other stimuli (such as chemistry, flow, cell-cell interactions) random cell migration would predominate [45]. The cell would migrate randomly within that zone but would not deviate far. In the same way, a cell initially placed in the left zone (c3d) moves away from the free side to the interior of the substrate, but once it crosses to the intermediate zone, it reverses and randomly migrates as in the previous subcase, becoming trapped around this interface. This change in the cell's migration pattern always occurs at the same $x$-coordinate, but at different $y$ - and $z$-coordinates due to the randomness of the cell movement (see figure 8).

\section{Traction forces and cell speed}

Our model predicts that traction forces increase with higher substrate stiffness until saturation (figure $5(A)$ ), which has previously been reported in experiments [9, 16, 68]. We also predict a biphasic dependence of cell migration speed on substrate compliance, as reported in [69]. In all the analyzed examples, the cell exerts higher forces while moving in the stiffer substrate.

When a cell moving in the softer substrate approaches and crosses an interface where Young's modulus changes (as happens in $c 1 a, c 2 b$ and $c 3 b$ ), the traction force increases abruptly. When the new value is reached, it remains nearly constant as the cell migrates further into the stiffer zone. Traction forces are about $0.015 \mu \mathrm{N}$ on the more compliant side $(0.001 \mathrm{MPa})$ and $0.055 \mu \mathrm{N}$ on the stiffer one $(0.04 \mathrm{MPa})$ which correspond with speeds of $0.21 \mu \mathrm{m} \mathrm{min} \min ^{-1}$ and $0.67 \mu \mathrm{m} \mathrm{min}^{-1}$, respectively (reference line of figure $5(B)$ ). The work developed in [9] in a 2D substrate with different rigidities shows good agreement with the values of traction forces and cell speeds in the range of their study. They measured a maximum traction stress of $1.09 \pm 0.34 \mathrm{kPa}$ and a maximum cell speed of $0.54 \pm 0.13 \mu \mathrm{m} \mathrm{min}^{-1}$ for a $0.03 \mathrm{MPa}$ substrate stiffness. The corresponding computational values in our model are $0.662 \mathrm{kPa}$ and $0.67 \mu \mathrm{m} \mathrm{min}^{-1}$, respectively. Similar speed ranges were found in [69] with a maximal of $0.72 \pm 0.06 \mu \mathrm{m} \mathrm{min}^{-1}$ for $0.021 \mathrm{MPa}$ substrate stiffness. In addition, they suggested that optimal stiffness for maximum migration is shifted depending on the concentration of the ECM protein covalently attached to the substrate. However, we have to keep in mind that we are comparing 2D and 3D speeds. The recent literature $[27,28]$ demonstrates the low correlation between $2 \mathrm{D}$ and $3 \mathrm{D}$ motility, suggesting that 2D studies are poor predictors of 3D speeds. Nevertheless, they found $3 \mathrm{D}$ cell speeds similar to those obtained in our model (specifically $0.3-0.8 \mu \mathrm{m} \mathrm{min}^{-1}$ in [27] and 0.2-0.7 $\mu \mathrm{m} \mathrm{min}^{-1}$ in [28]).

A direct quantitative comparison of cell speeds is difficult, due to the significant variability observed in the experiments as a function of thr cell type, substrate composition or morphology. In fact, in [28] they studied the cell behavior in four different ECMs (cell-derived matrix, matrigel, collagen, fibrin) and they concluded that considering the molecular composition of the matrix is crucial for a 3D cell migration study. Similar conclusions can also be found
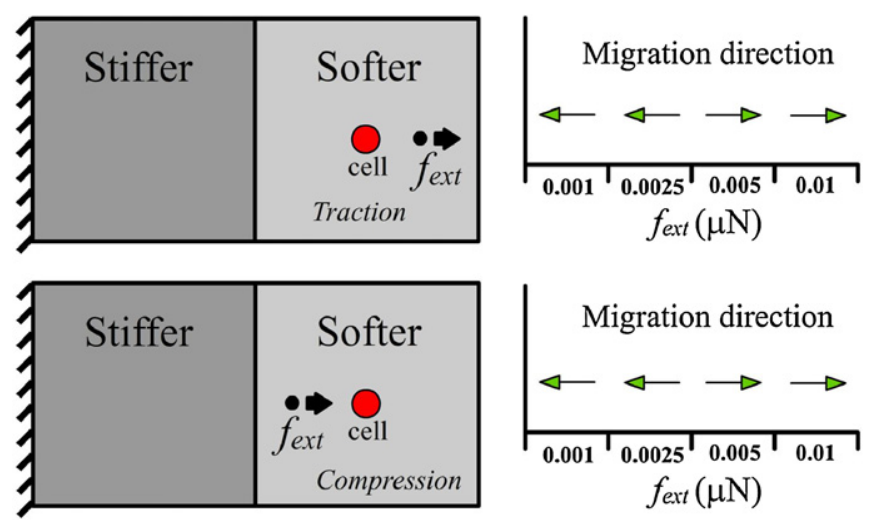

Figure 9. Scheme corresponding to case 1, showing the relative position of a micro-needle and the direction of the applied force. Inserting into the substrate a micro-needle and applying a lateral force can modify the behavior of the cell and even change its migration direction.

in $[3,70,71]$, which studied the influence of geometrical and mechanical properties of the microenvironment on 3D migration. Interestingly, in spite of different conditions and cell types, similar ranges (comparable with our results) of cell speeds were found $\left(0.1-0.26 \mu \mathrm{m} \mathrm{min} \mathrm{min}^{-1}\right.$ in [70], $0.1-0.8 \mu \mathrm{m} \mathrm{min}^{-1}$ in [71] and $0.2-1.0 \mu \mathrm{m} \mathrm{min}^{-1}$ in [3]).

\section{External forces}

All the previous results correspond to isolated cells under different mechanical conditions, focusing on the boundary conditions and the elasticity of the ECM. Here, we aim to understand the effect of applying external loads on specific locations inside the matrix surrounding a single cell. In particular, relevant in this respect is the work of Lo et al [9], where they demonstrated that inserting a micro-needle near the cell and stretching/pushing it, can modify its behavior and even change completely its migration direction. In order to test our model under external forces, we simulate the insertion of a micro-needle by means of the application of one local external force applied at a distance of $40 \mu \mathrm{m}$ from the cell, which is maintained constant throughout the simulation. The conditions of the substrate are exactly the same as those used in the case 1 (specifically c1a). We find that with a sufficient level of applied force, the micro-needle is able, as was shown by [9], to change the direction of the cell movement. In the simulated case, the cell tends to migrate toward the stiffer substrate (left). When the stretching (or pushing) force exceeds a certain threshold value (specifically $0.005 \mu N$ ), the cell changes its migration trend (figure 9). As expected, similar results are obtained varying the distance between the cell and the microneedle (data not shown), where further distances are equivalent to lower forces.

\section{Discussion}

Although cell migration phenomena involve many different and complex mechanisms, here, we present a simplified model capable of simulating the preferential movement of an 
individual cell in 3D under different mechanical conditions. This simplification is based on the hypothesis that mechanosensing is the main regulatory mechanism to direct cell movement. In fact, we consider three relevant phenomena: mechano-sensing, CSK remodeling and migration, and solve their corresponding equations separately and sequentially (since the mechano-sensing defines the CSK remodeling and both define the migration). First, during mechano-sensing, the stress equilibrium between the cell, substrate and external forces is satisfied. Depending on the mechanical properties and boundary conditions, different strain/displacement fields and values of forces exerted by the cell on the ECM/substrate $p_{\text {cell }}$ are obtained in each step. With these data, the CSK remodels and reorients, updating the internal variable that describes the preferential orientation of the cell $\boldsymbol{d}_{\text {pol }}$. Once the values of $p_{\text {cell }}$ and $\boldsymbol{d}_{\mathrm{pol}}$ are obtained, the traction forces are evaluated, and by satisfying the equilibrium of forces acting on the cell, we compute its speed.

Consistent with our model is the observation that traction forces increase with substrate stiffness [9, 16, 68]. Without external loads, the cell strain is always negative (contractile) since the AM system is always active to reduce the dimensions of the cell. Therefore, stiffer substrates lead to lower values of strain (closer to zero), higher values of $p_{\text {cell }}$ and consequently to higher values of the traction exerted $\left(\boldsymbol{F}_{\text {trac }}\right)$. In the presented cases, cell speed is higher in the stiffer substrate. However, the elastic modulus of the stiffer side $\left(E_{2}\right)$ was selected to reach maximum velocities with the reference values used in the model. Using a higher value of stiffness would lead to lower speeds, which could be even lower than in the softer substrate due to the increase in viscosity and the saturation of forces (see figure $5(B)$ ). Of course, a stiffer matrix would also tend to be more difficult to enzymatically degrade and may have different transport properties and density of adhesive ligand, all of which could influence the migration speed. It is important to note here that the presented calculations only examine mechanical effects, thereby down-playing other additional factors.

Recent experimental works [27, 28] have quantitatively demonstrated the main differences between 2D and 3D cell migration. The lack of correlation between $2 \mathrm{D}$ and 3D motility suggests that focal adhesion proteins may regulate motility in a matrix in a manner fundamentally different from that in planar cell motility. Nevertheless, 2D studies are still useful and, in some respects, comparable to 3D (directionality, number of adhesions, adhesion axial ratio and even adhesion area [28]). Here, we compare some of our results and predictions with the experimental data on 2D developed in [9]. These experiments consist of $2 \mathrm{D}$ substrates with two different rigidities, where some isolated cells (only interacting with the ECM) are embedded. Their findings indicate that cells placed in the softer part of the substrate tend to migrate toward the stiffer part and cross the interface which separates the substrates, whereas cells placed in the stiffer zone do not cross this interface. This suggests, as we propose, that cells are capable of sensing the mechanical properties of their surroundings and tend to move toward stiffer substrates. As the only forces acting on the substrate are those exerted by the cell itself, its movement is governed by the local mechanical environment, the boundary conditions and the mechanical properties of the ECM. In fact, it has been investigated in recent experiments $[3,27,28,70,71]$ how microarchitecture, local mechanical properties and molecular composition influence cell migration behavior. Our main assumption is that the cell aligns with the direction of principal strain and moves according to the relative displacements between the cell body and its centroid, which depend on imposed boundary conditions and local changes in substrate stiffness. The recent literature suggests that elasticity, boundary conditions and perhaps embedded fibers can modulate the apparent elasticity of matrices that cells are likely to sense [47]. In all the cases we have shown, cell migration follows our criterion, in agreement with those experimental observations (figure 8). For example in the second case, there are two zones with an interface located in the middle of the softer side, where the local displacement field is modified due to the right constraint. When a cell is located near that constraint, the cell senses it and moves to the right, whereas if located further away, it moves to the left, where Young's modulus is higher $\left(E_{2}\right)$ and there is also a constraint. Note how in the third case, where the stiffer side (left) is free of constraints, a third zone appears. The substrate displacement field obtained by the mechano-sensing analysis, reaches a minimum in the middle of the stiffer substrate. As a result, the opposing gradients of displacements cause a cell to move randomly around this location. This happens when the cell reaches a zone in the substrate with similar mechanical conditions in all directions. With no differences in local mechanical properties (and absence of other stimuli such as chemistry, flow, cell-cell interactions, etc), the cell would not be able to decide where to move and random migration would be predominant [45].

The magnitude of cell speed for the reference values of parameters used in our model ranges from 0.2 to $0.7 \mu \mathrm{m} \mathrm{min}^{-1}$, showing good agreement with experimental data [3, 9, 27, 28, 69-71]. The wide range of parameters used in the model, allows adapting it to different conditions and/or experiments, taking into account the limitations discussed below.

The model is also used to study the case in [9], where local forces are applied in the cell surroundings to understand their role on the preferential movements of single cells. A blunted micro-needle is introduced in the substrate near the cell and moves toward or away from the cell to modify the local state of stress in the ECM. Experiments show that the cell moves toward the pulling forces, and away from the pushing forces. As we have shown in the results section, our model is able to predict this effect and helps to explain it. If the microneedle pulls, the compressive forces of the cell oppose the needle forces. Hence, the local displacement field changes in a way that the cell senses the forces induced by the needle as if they were a constraint, and therefore the cell's CSK polarizes to move toward the needle. However, if the micro-needle pushes, the compression forces of the cell follow the same direction as those of the micro-needle. This causes the cell to sense lower rigidity in the direction of the micro-needle, even though Young's modulus is the same in all directions. Hence, the cell reorients and moves away from the needle. The distance and the magnitude of the applied forces determine the 
local mechanical environment and, therefore, regulate whether or not the cell changes its behavior.

Nevertheless, we have to keep in mind that cell migration in $3 \mathrm{D}$ is a complex process where multiple phenomena are involved. Cell type, molecular composition, morphology and microarchitecture of the ECM/substrate each contribute to determine the migration behavior and, therefore, some simplifications are necessary. Next, we briefly describe some of the simplifications assumed in this model in order to understand their implications to our conclusions. First, we have focused on the modeling of mechano-sensing as the main regulatory mechanism of cell migration. Clearly other mechanisms, such as chemistry [35], biochemical gradients [72, 73] or fluid flow [74], all influence individual cell migration in $3 \mathrm{D}$. However, the consideration of these mechanisms does not affect the results obtained in the present numerical studies, where we only focused on analyzing the effect of different mechanical conditions in the absence of these other effects. We leave the addition of these effects as future work toward a more comprehensive model under different environmental conditions. Second, when one cell migrates in $3 \mathrm{D}$, the matrix is degraded due to the action of proteases released by the cell [75], while at the same time, the cell produces and secretes new matrix, remodeling and altering the structure and stiffness of the matrix around it $[72,76]$. As a first approximation, we have not considered these effects on single-cell migration. While recognized to be important, these other effects could be added without having significant impact on the current predictions, to the extent that they can be considered as acting independently. While we can present no evidence to support this assumption at this time, it seems a useful approach to begin with. In addition, we have not simulated mechano-biological phenomena associated with the evolution of the area of adhesion between the cell and matrix [57] and we have not considered the change of cell shape as a consequence of its deformation. For simplicity, we considered the cell occupying a spherical volume and modeled the sphere as a regular hexahedron, whose shape and size do not change with time. Cell shape and other factors (such as cell stress or ECM/substrate stiffness) could affect the reorientation $(\kappa)$ of the CSK, but this parameter was considered constant in our simulations for simplicity. Finally, we have focused on the modeling of biased migration of single cells in $3 \mathrm{D}$; however, when cell populations migrate collectively, much more complex events are involved, such as cell-cell interactions [43, 47].

Therefore, the model presented here is only one step in the challenging task of modeling 3D cell migration. So far, and despite the simplifications assumed, we are able to predict different 3D migration patterns of single cells as a function of the local mechanical environment defined by the mechanical properties of the ECM, the boundary conditions and the application of local external forces. As such, the present model attempts to understand the role of different mechanical conditions in 3D cell migration, being a potential tool for the development of biomaterial scaffolds for different applications in tissue engineering and biomedical research.

\section{Acknowledgments}

This research was supported by the Spanish Ministry of Science and Innovation (DPI 2009-14115-CO3-01) and the FPI grant (BES-2010-029927)(project part financed by the European Union, European Regional Development Fund). The authors also acknowledge the support of the SingaporeMIT Alliance for Research and Technology.

\section{References}

[1] Lauffenburger D A and Horwitz A F 1996 Cell migration: a physically integrated molecular process Cell 84 359-69

[2] Even-Ram S and Yamada K M 2005 Cell migration in 3d matrix Curr. Opin. Cell Biol. 17 524-32

[3] Ehrbar M, Sala A, Lienemann P, Ranga A, Mosiewicz K, Bittermann A, Rizzi S C, Weber F E and Lutolf M P 2011 Elucidating the role of matrix stiffness in $3 \mathrm{~d}$ cell migration and remodeling Biophys. J. 100 284-93

[4] Ingber D E 2010 From cellular mechanotransduction to biologically inspired engineering Ann. Biomed. Eng. 38 1148-61

[5] Discher D E, Janmey P and Wang Y L 2005 Tissue cells feel and respond to the stiffness of their substrate Science 310 1139-43

[6] Bershadsky A D, Balaban N Q and Geiger B 2003 Adhesion-dependent cell mechanosensitivity Annu. Rev. Cell Dev. Biol. 19 677-95

[7] Yang T Y and Zaman M H 2007 Free energy landscape of receptor-mediated cell adhesion J. Chem. Phys. 126045103

[8] Yang T Y and Zaman M H 2010 Estimation of cellular adhesion forces using mean field theory Cell. Mol. Bioeng. 3 190-4

[9] Lo C M, Wang H B, Dembo M and Wang Y L 2000 Cell movement is guided by the rigidity of the substrate Biophys. J. 79 144-52

[10] Engler A, Bacakova L, Newman C, Hategan A, Griffin M and Discher D 2004 Substrate compliance versus ligand density in cell on gel responses Biophys. J. 86 617-28

[11] Yeung T, Georges P C, Flanagan L A, Marg B, Ortiz M, Funaki M, Zahir N, Ming W Y, Weaver V and Janmey P A 2005 Effects of substrate stiffness on cell morphology, cytoskeletal structure, and adhesion Cell Motil. Cytoskeleton 60 24-34

[12] Saez A, Ghibaudo M, Buguin A, Silberzan P and Ladoux B 2007 Rigidity-driven growth and migration of epithelial cells on microstructured anisotropic substrates Proc. Natl Acad. Sci. USA 104 8281-6

[13] Janmey P A, Winer J P, Murray M E and Wen Q 2009 The hard life of soft cells Cell Motil. Cytoskeleton 66 597-605

[14] Baker E L, Bonnecaze R T and Zaman M H 2009 Extracellular matrix stiffness and architecture govern intracellular rheology in cancer Biophys. J. 97 1013-21

[15] Sanz-Herrera J A, Moreo P, Garcia-Aznar J M and Doblare M 2009 On the effect of substrate curvature on cell mechanics Biomaterials 30 6674-86

[16] Mitrossilis D, Fouchard J, Guiroy A, Desprat N, Rodriguez N, Fabry B and Asnacios A 2009 Single-cell response to stiffness exhibits muscle-like behavior Proc. Natl Acad. Sci. USA 106 18243-8

[17] Harunaga J S and Yamada K M 2011 Cell-matrix adhesions in 3d Matrix Biol. 30 363-8

[18] Cukierman E, Pankov R, Stevens D R and Yamada K M 2001 Taking cell-matrix adhesions to the third dimension Science 294 1708-12

[19] Bischofs I B and Schwarz U S 2003 Cell organization in soft media due to active mechanosensing Proc. Natl Acad. Sci. USA 100 9274-9 
[20] Schwarz U S and Bischofs I B 2005 Physical determinants of cell organization in soft media Med. Eng. Phys. 27 763-72

[21] Freyman T M, Yannas I V, Yokoo R and Gibson L J 2002 Fibroblast contractile force is independent of the stiffness which resists the contraction Exp. Cell Res. 272 153-62

[22] Saez A, Buguin A, Silberzan P and Ladoux B 2005 Is the mechanical activity of epithelial cells controlled by deformations or forces? Biophys. J. 89 L52-4

[23] De R, Zemel A and Safran S A 2008 Do cells sense stress or strain? Measurement of cellular orientation can provide a clue Biophys. J. 94 L29-31

[24] Riveline D, Zamir E, Balaban N Q, Schwarz U S, Ishizaki T, Narumiya S, Kam Z, Geiger B and Bershadsky A D 2001 Focal contacts as mechanosensors: externally applied local mechanical force induces growth of focal contacts by an mdia1-dependent and rock-independent mechanism J. Cell Biol. 153 1175-85

[25] Kaverina I, Krylyshkina O, Beningo K, Anderson K, Wang Y L and Small J V 2002 Tensile stress stimulates microtubule outgrowth in living cells $J$. Cell Sci. 115 2283-91

[26] Simpson M J, Towne C, McElwain D L S and Upton Z 2010 Migration of breast cancer cells: understanding the roles of volume exclusion and cell-to-cell adhesion Phys. Rev. E 82041901

[27] Fraley S I, Feng Y, Krishnamurthy R, Kim D-H, Celedon A, Longmore G D and Wirtz D 2010 A distinctive role for focal adhesion proteins in three-dimensional cell motility Nature Cell Biol. 12 598-604

[28] Hakkinen K M, Harunaga J S, Doyle A D and Yamada K M 2011 Direct comparisons of the morphology, migration, cell adhesions, and actin cytoskeleton of fibroblasts in four different three-dimensional extracellular matrices Tissue Eng. A 17 713-24

[29] Friedl P and Brocker E B 2000 The biology of cell locomotion within three-dimensional extracellular matrix Cell. Mol. Life Sci. 57 41-64

[30] Cukierman E, Pankov R and Yamada K M 2002 Cell interactions with three-dimensional matrices Curr. Opin. Cell Biol. 14 633-9

[31] Vickerman V, Blundo J, Chung S and Kamm R D 2008 Design, fabrication and implementation of a novel multi-parameter control microfluidic platform for three-dimensional cell culture and real-time imaging $L a b$ Chip 8 1468-77

[32] Chung S, Sudo R, Vickerman V, Zervantonakis I K and Kamm R D 2010 Microfluidic platforms for studies of angiogenesis, cell migration, and cell-cell interactions Ann. Biomed. Eng. 38 1164-77

[33] Zaman M H, Kamm R D, Matsudaira P and Lauffenburger D A 2005 Computational model for cell migration in three-dimensional matrices Biophys. $J$. 89 1389-97

[34] Rangarajan R and Zaman M H 2008 Modeling cell migration in 3d: status and challenges Cell Adhes. Migr. 2 106-9

[35] Harjanto D and Zaman M H 2010 Computational study of proteolysis-driven single cell migration in a three-dimensional matrix Ann. Biomed. Eng. 38 1815-25

[36] Groh A and Wagner M 2011 Biased three-dimensional cell migration and collagen matrix modification Math. Biosci. 231 105-19

[37] Manoussaki D 2003 A mechanochemical model of angiogenesis and vasculogenesis Esaim: Math. Modelling Numer. Anal. 37 581-99

[38] Moreo P, Garcia-Aznar J M and Doblare M 2008 Modeling mechanosensing and its effect on the migration and proliferation of adherent cells Acta Biomater. 4 613-21
[39] Häcker A 2011 A mathematical model for mesenchymal and chemosensitive cell dynamics J. Math. Biol. doi:10.1007/s00285-011-0415-7

[40] Chopard B, Ouared R, Deutsch A, Hatzikirou H and Wolf-Gladrow D 2010 Lattice-gas cellular automaton models for biology: from fluids to cells Acta Biotheoretica 58 329-40

[41] Chen N, Glazier J A, Izaguirre J A and Alber M S 2007 A parallel implementation of the cellular Potts model for simulation of cell-based morphogenesis Comput. Phys. Commun. 176 670-81

[42] Merks R M H and Koolwijk P 2009 Modeling morphogenesis in silico and in vitro: towards quantitative, predictive, cell-based modeling Math. Modelling Natural Phenom. 4 149-71

[43] Palsson E 2001 A three-dimensional model of cell movement in multicellular systems Future Gener. Comput. Syst. 17 835-52

[44] Sen S, Engler A J and Discher D E 2009 Matrix strains induced by cells: computing how far cells can feel Cell. Mol. Bioeng. 2 39-48

[45] Petrie R J, Doyle A D and Yamada K M 2009 Random versus directionally persistent cell migration Nature Rev. Mol. Cell Biol. 10 538-49

[46] Friedl P and Wolf K 2010 Plasticity of cell migration: a multiscale tuning model J. Cell Biol. 188 11-9

[47] Buxboim A, Ivanovska I L and Discher D E 2010 Matrix elasticity, cytoskeletal forces and physics of the nucleus: how deeply do cells 'feel' outside and in? J. Cell Sci. 123 297-308

[48] Wang N, Naruse K, Stamenovic D, Fredberg J J, Mijailovich S M, Toric-Norrelykke I M, Polte T, Mannix R and Ingber D E 2001 Mechanical behavior in living cells consistent with the tensegrity model rid b-6966-2008 Proc. Natl Acad. Sci. USA 98 7765-70

[49] Heng Y W and Koh C G 2010 Actin cytoskeleton dynamics and the cell division cycle rid a-2215-2011 Int. J. Biochem. Cell Biol. 42 1622-33

[50] Damania D, Subramanian H, Tiwari A K, Stypula Y, Kunte D, Pradhan P, Roy H K and Backman V 2010 Role of cytoskeleton in controlling the disorder strength of cellular nanoscale architecture rid b-6689-2009 Biophys. J. 99 989-96

[51] Burnette D T, Burnette D T, Manley S, Sengupta P, Sougrat R, Davidson M W, Kachar B and Lippincott-Schwartz J 2011 A role for actin arcs in the leading-edge advance of migrating cells Nature Cell Biol. 13 371-82

[52] Astrom J A, Kumar P B S, Vattulainen I and Karttunen M 2008 Strain hardening, avalanches, and strain softening in dense cross-linked actin networks Phys. Rev. E 77051913

[53] Astrom J A, Kumar P B S and Karttunen M 2009 Aster formation and rupture transition in semi-flexible fiber networks with mobile cross-linkers Soft Matter 5 2869-74

[54] Kim T, Hwang W and Kamm R D 2009 Computational analysis of a cross-linked actin-like network Exp. Mech. 49 91-104

[55] Kim T, Hwang W, Lee H and Kamm R D 2009 Computational analysis of viscoelastic properties of crosslinked actin networks PLoS Comput. Biol. 5 e1000439

[56] Deshpande V S, McMeeking R M and Evans A G 2006 A bio-chemo-mechanical model for cell contractility Proc. Natl Acad. Sci. USA 103 14015-20

[57] McGarry J P, Fu J, Yang M T, Chen C S, McMeeking R M, Evans A G and Deshpande V S 2009 Simulation of the contractile response of cells on an array of micro-posts Phil. Trans. R. Soc. A 367 3477-97 
[58] Hill A V 1938 The heat of shortening and the dynamic constants of muscle Proc. R. Soc. B 126 136-95

[59] Rassier D E, MacIntosh B R and Herzog W 1999 Length dependence of active force production in skeletal muscle J. Appl. Physiol. 86 1445-57

[60] Wang J H C, Goldschmidt-Clermont P and Yin F C P 2000 Contractility affects stress fiber remodeling and reorientation of endothelial cells subjected to cyclic mechanical stretching Ann. Biomed. Eng. $281165-71$

[61] Hayakawa K, Sato N and Obinata T 2001 Dynamic reorientation of cultured cells and stress fibers under mechanical stress from periodic stretching Exp. Cell Res. 268 104-14

[62] Yoshigi M, Hoffman L M, Jensen C C, Yost H J and Beckerle M C 2005 Mechanical force mobilizes zyxin from focal adhesions to actin filaments and regulates cytoskeletal reinforcement J. Cell Biol. 171 209-15

[63] De R, Zemel A and Safran S A 2007 Dynamics of cell orientation Nature Phys. 3 655-9

[64] Dokukina I V and Gracheva M E 2010 A model of fibroblast motility on substrates with different rigidities Biophys. $J$. 98 2794-803

[65] Schmidt C E, Horwitz A F, Lauffenburger D A and Sheetz M P 1993 Integrin cytoskeletal interactions in migrating fibroblasts are dynamic, asymmetric, and regulated J. Cell Biol. 123 977-91

[66] Schafer A and Radmacher M 2005 Influence of myosin ii activity on stiffness of fibroblast cells Acta Biomater. $1273-80$

[67] Maskarinec S A, Franck C, Tirrell D A and Ravichandran G 2009 Quantifying cellular traction forces in three dimensions Proc. Natl Acad. Sci. USA 106 22108-13
[68] Webster K D, Crow A and Fletcher D A 2011 An AFM-based stiffness clamp for dynamic control of rigidity PLoS One 6 e17807

[69] Peyton S R and Putnam A J 2005 Extracellular matrix rigidity governs smooth muscle cell motility in a biphasic fashion rid e-8643-2010 J. Cell. Physiol 204 198-209

[70] Harley B A C, Kim H D, Zaman M H, Yannas I V, Lauffenburger D A and Gibson L J 2008

Microarchitecture of three-dimensional scaffolds influences cell migration behavior via junction interactions Biophys. $J$. 95 4013-24

[71] Peyton S R, Ilke Kalcioglu Z, Cohen J C, Runkle A P, Van Vliet K J, Lauffenburger D A and Griffith L G 2011 Marrow-derived stem cell motility in $3 \mathrm{~d}$ synthetic scaffold is governed by geometry along with adhesivity and stiffness Biotechnol. Bioeng. 108 1181-93

[72] Groh A and Louis A K 2010 Stochastic modelling of biased cell migration and collagen matrix modification J. Math. Biol. $61617-47$

[73] Roussos E T, Condeelis J S and Patsialou A 2011 Chemotaxis in cancer Nature Rev. Cancer 11 573-87

[74] Polacheck W J, Charest J L and Kamm R D 2011 Interstitial flow influences direction of tumor cell migration through competing mechanisms Proc. Natl Acad. Sci. USA 108 11115-20

[75] Wood L B, Das A, Kamm R D and Asada H H 2009 A stochastic broadcast feedback approach to regulating cell population morphology for microfluidic angiogenesis platforms IEEE Trans. Biomed. Eng. 56 2299-303

[76] Dallon J C, Sherratt J A and Maini P K 1999 Mathematical modelling of extracellular matrix dynamics using discrete cells: fiber orientation and tissue regeneration $J$. Theor. Biol. 199 449-71 